\title{
CHALLENGES IN E-GOVERNMENT AND SECURITY OF INFORMATION
}

\author{
Min-Shiang HWANG, Chun-Ta LI, Jau-Ji SHEN, and Yen-Ping CHU
}

\begin{abstract}
Due to the advances made in Information and Communication Technologies (ICT), e-Government users can easily use the available services from places and at time that are convenient to them through WWW browsers. To easily and securely provide the required services through Information Technology (IT) has been an important issue in e-Government. In this article, the authors propose an explicit classification of e-Government applications and some challenges and obstacles in e-Government considered from four perspectives. Finally, a comprehensive view of some critical success factors in e-Government is proposed.
\end{abstract}

Keywords: e-Government; Critical Success Factor; Internet; Security.

\section{Introduction}

The time for the electronic-based society has arrived. E-Government has received more and more importance and it can provide a non-stop government information services to citizens, enterprises, public officers, government administrations and agencies over a network. There are many issues in e-Government which need a careful examination such as security issues, ${ }^{1,2,3}$ service requirements of e-Government, ${ }^{4,5,6}$ e-Government model, ${ }^{7,8,9,10,11,12,13}$ strategy and policy for e-Government, ${ }^{14,15,16,17}$ and domain of e-Government. ${ }^{18}$

In this article, we focus on the challenges, obstacles, and Critical Success Factors $(\mathrm{CSFs})^{19}$ in e-Government. First of all, we have to consider all of the participants in an e-Government system. According to the involved communities, an explicit classification of e-Government applications is proposed. It provides a way to an understanding of the challenges and CSFs in e-Government. Further detailed classification of e-Government applications is provided in a subsequent section. Then the challenges and obstacles in e-Government are considered from four perspectives. The CSFs of e-Government are described next. Finally, the last section provides conclusions and outlines future research directions. 


\section{An Explicit Classification of e-Government Applications}

In order to develop an e-Government system, first, all of the users that may use the eGovernment system have to be known. Therefore, the authors have defined four basic involved communities: Government, Officeholder, Citizens, and Business. All of the applications in an e-Government system will be developed in accordance with these four communities. An explicit classification of the e-Government applications is illustrated in Figure 1 and the detailed description of each e-Government application is as given below.

\section{Government-to-Government e-Government (G-to-G e-Gov)}

Government-to-Government e-Government (G-to-G e-Gov) supports the exchange of information between the inter-organizational governmental departments, such as the system of official documents received and dispatched.

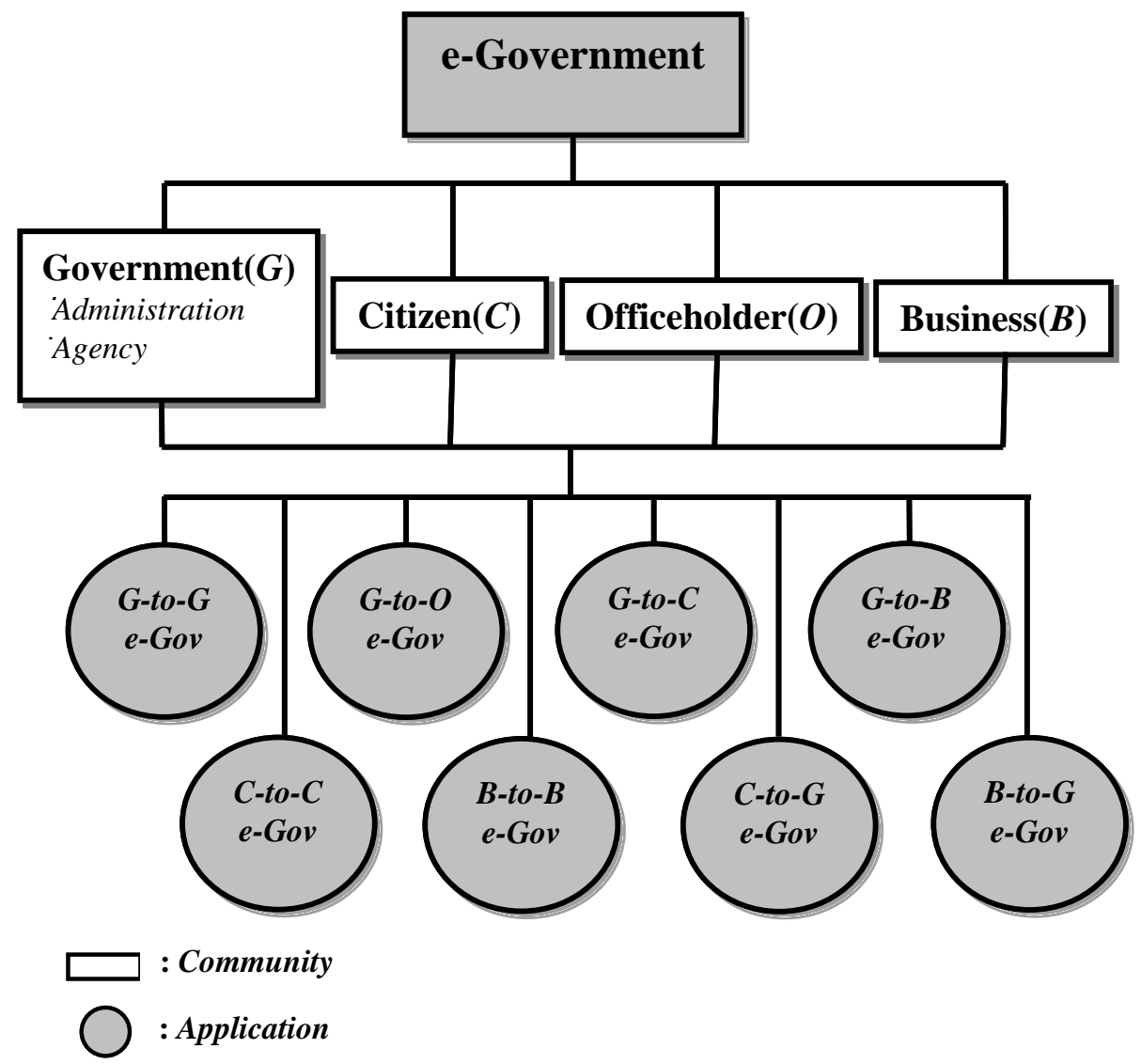

Figure 1: An Explicit Classification of e-Government Applications. 


\section{Government-to-Officeholder e-Government (G-to-O e-Gov)}

Government-to-Officeholder e-Government (G-to-O e-Gov) supports intraorganizational government officeholders, public affair organizations, and secondary organizations' cooperative processes and procedures of public affairs.

\section{Government-to-Citizen e-Government (G-to-C e-Gov)}

Citizens are aware of the services provided by the government through the communication network and use the service with their personal identities through secure mechanisms. E-Voting and e-Assistance are two examples.

\section{Government-to-Business e-Government (G-to-B e-Gov)}

Businesses are aware of the services provided by the government through the communication network and use the service with a legal person's identity through secure mechanisms. Examples are on-line customs declaration of goods or on-line clearance of goods.

\section{Citizen-to-Citizen e-Government (C-to-C e-Gov)}

In Citizen -to- Citizen e-Government, the Government acts in a mediator role for the exchange of information. Typical examples are the following ones: the Government acts as a trouble-shooter in citizens' dispute or the Government offers temporary jobs to the victims of a disaster, so they could work in the public sector or private businesses. In this type of application the Government is a mediator that offers help in terms of manpower and information.

\section{Business-to-Business e-Government (B-to-B e-Gov)}

Similar to the above-described application of C-to-C e-Government, in Business-to-Business e-Government the Government plays an intermediary role in the exchange of information. For example, the Government could invite the business to bid for contracts that contain sensitive information. These businesses might produce the country's weaponry, such as tanks, warships, and warplanes.

\section{Citizen-to-Government e-Government (C-to-G e-Gov)}

These electronic communities are formed based on the demand of the citizens (demand aggregate-driven). Citizens request assistance or give suggestions to the citizenry, for example.

\section{Business-to-Government e-Government (B-to-G e-Gov)}

Similar to the above-mentioned application of C-to-G e-Government, electronic communities are formed on the basis of the demands of the business (demand aggregate-driven). Businesses ask for governmental patronage or proposals from other businesses, for example. 


\section{Challenges and Obstacles in e-Government}

Considering the types of applications of e-Government described in the previous section, the authors demonstrate some challenges and obstacles to e-Government viewed from four perspectives: technical, political, cultural, and legal aspects. There is some difference between the aspects proposed here and the four aspects proposed by Wimmer and von Bredow ${ }^{20}$ : social, political, cultural, and legal aspects. The challenges and obstacles in e-Government are illustrated in Figure 2 and further explanation of the challenges and obstacles in e-Government is provided below.

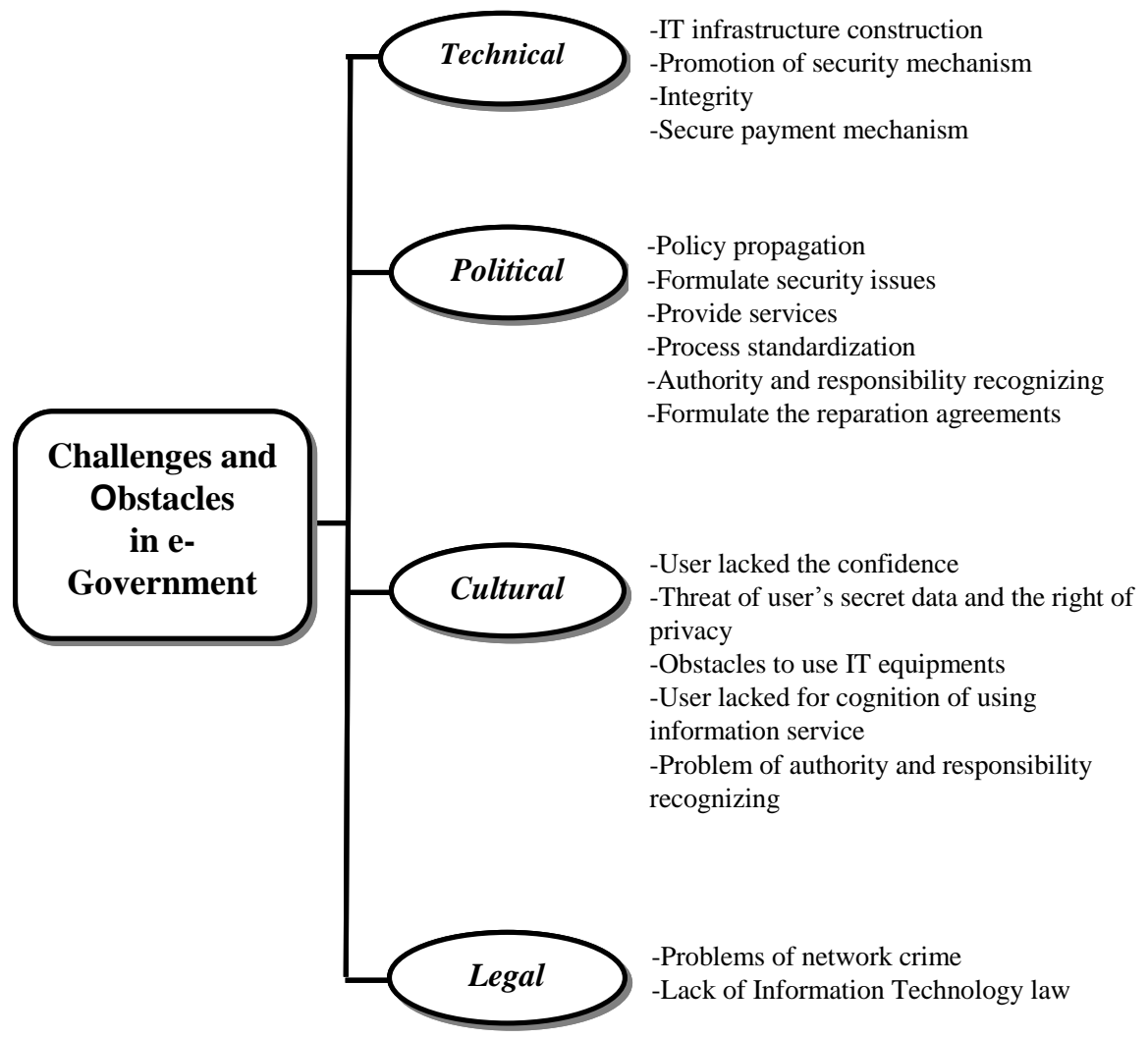

Figure 2: Challenges and Obstacles in e-Government.

\section{Technical Impacts}

In order to introduce and promote e-Government, the first and very important step is to construct the relevant IT infrastructure. This is a requirement very similar to the 
relationship between advances in urban development and the construction of appropriate road infrastructure. Furthermore, system and security requirements, such as integrity, secure payment mechanism, ${ }^{21,22,23,24}$ and promotion of security mechanism, are pertinent to e-Government as well.

\section{Political Impacts}

As is evident from Figure 2, there are many political issues that have to be considered. In this aspect, the services and processes need careful consideration. If the eGovernment can provide a rich variety of different services (e-Justice for example) it will be more acceptable and convenient to users.

From the user's point of view, process standardization is a must and the simple principle "easy-to-use" has to be kept. Finally, the agreements of reparations, authority, and responsibilities have to be clearly formulated and recognized in order to protect the user's right.

\section{Cultural Impacts}

From this perspective, the challenges and obstacles in e-Government bring a lot of difficulty because it involves the human psychological factor. Therefore, the eGovernment should not make any mistakes here, or otherwise it fails. Furthermore, the important principle_- "easy-to-use"-has a great influence on the success of eGovernment. This principle could advertise and promote e-Government and it will allow more people to use the e-Government services. In short, even illiterate people can use e-Government without any worries.

\section{Legal Impacts}

This aspect embraces a lot of problems related to networking crime and security threats, ${ }^{25}$ such as hacker attacks, viruses, masquerades of unauthorized identity, and computer forgery. Furthermore, there is a shortage of relevant law in Information Technology.

\section{Critical Success Factors in e-Government}

In accordance with the e-Government challenges and obstacles described in the previous section, the critical success factors (CSF) in e-Government have to be investigated thoroughly. Therefore, we demonstrated thirteen CSFs in e-Government, as illustrated in Figure 3. These CSFs in e-Government are considered from a comprehensive view, including users, process, hardware/software, and legal views.

From the user's perspective, the government has to be greatly supportive and promoting first of all. Furthermore, it should have a high acceptance of users, clearly de- 
fined authority and responsibility of users and it has to enhance the user's information technology skills. Besides, the diversification of electronic means is very helpful to eGovernment, such as wireless communication, net-meeting, video conferencing, and video telephones. From the process view, high security, standardization and knowledge management are a must for e-Government; then come the provision of specific services and the emphasis of its quality. Furthermore, the establishment of national

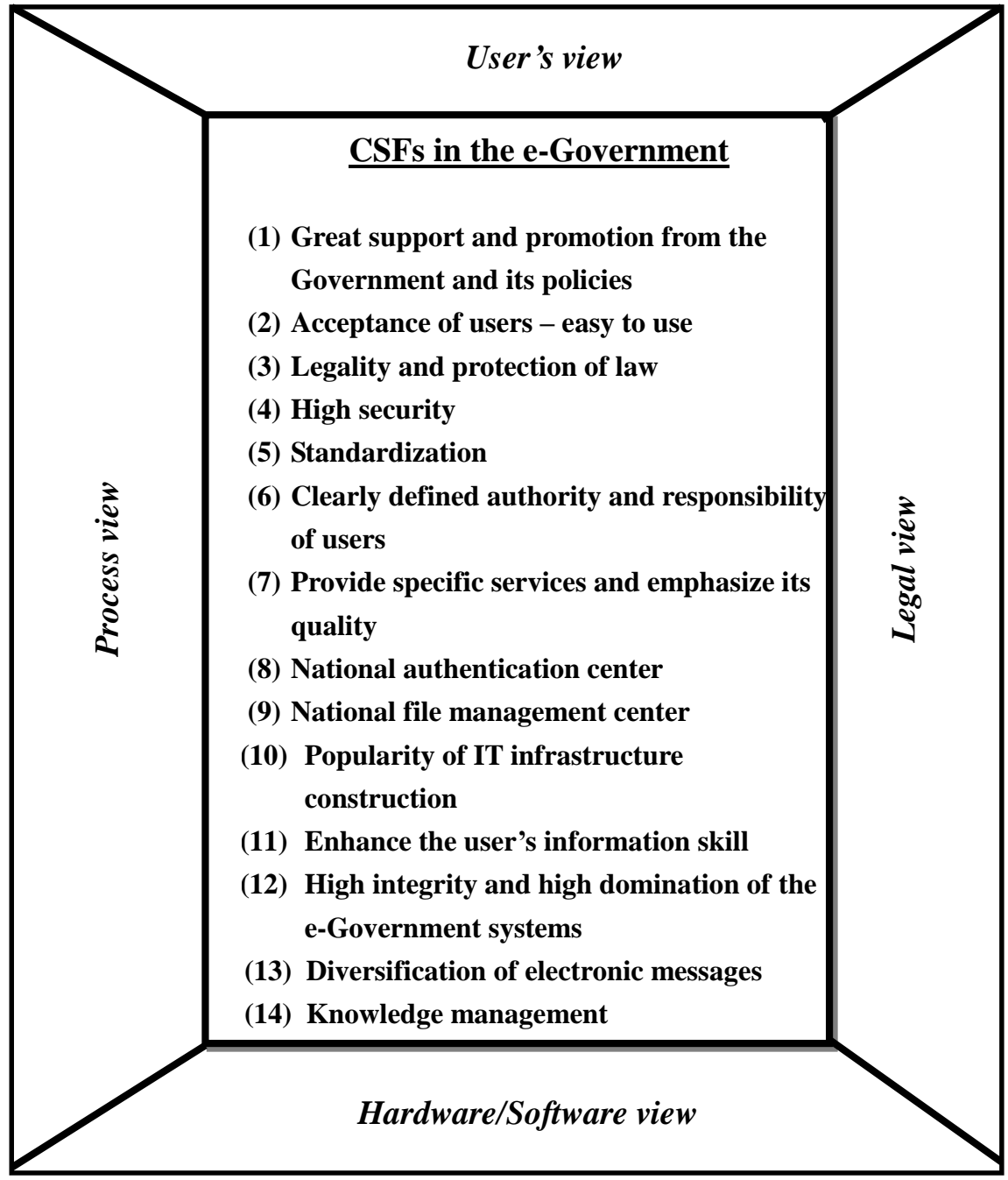

Figure 3: CSFs in e-Government from a Comprehensive View. 
authentication centre is an essential requirement, so as the users could use the services with their personal identities and all transactions are recorded in the national file management centre in order to protect the electronic documents from any damage. From the legal point of view, it is necessary to legislate for legitimacy; hence all people are equal before the law. Finally, from the hardware/software point of view, popularizing the IT infrastructure construction is essential for e-Government. In addition, it is important to enhance the integrity and the dominance of the e-Government system.

\section{Research Issues}

As to the future research work, the authors have outlined some research issues for further detailed consideration as follows. Included are security issues, issues of services provided, and the e-Government model.

- Security issues:

- Identification of security requirements ${ }^{26}$

- Attribute Certificates (AC) ${ }^{27}$

- Public Key Infrastructure (PKI) ${ }^{28,29,30}$

- Certification/Authentication ${ }^{31,32,33,34,35}$

- Risk analysis and Metrics for e-Government ${ }^{36}$

- Database Security $37,38,39,40$

- Issues of services provided:

- E-Learning in e-Government ${ }^{41}$

- E-Procurement in e-Government ${ }^{42}$

- Semantic Web for e-Government ${ }^{43}$

- E-Voting in e-Government ${ }^{44}$

- $\quad$ E-Government model. ${ }^{45,46,47,48}$

\section{Conclusion}

In this article, the authors have proposed an explicit classification of e-Government applications according to the involved participants in an e-Government system. Further, the authors have demonstrated the challenges and obstacles in e-Government considered from four aspects: technical, political, cultural, and legal aspects. In addition to outlining the challenges and obstacles in e-Government, they have proposed thirteen CSFs in e-Government from a comprehensive view: user, process, legal and hardware/software views. Finally, developing practical solutions in e-Government is a very interesting subject for further investigation and discussion. 


\section{Notes:}

1 Dorothy E. Denning and Peter J. Denning, Internet Besieged: Countering Cyberspace ScofflFaws (ACM Press, Addison Wesley Professional., 1998).

2 Stefanos Gritzalis and Costas Lambrinoudakis, "Security Requirements of e-Government Services: An Organizational Framework," in Proceedings of the International Conference on Parallel and Distributed Processing Techniques and Applications (PDPTA'2002) (Las Vegas, Nevada, USA, 24-27 June 2002), Volume 1, ed. Hamid R. Arabnia (CSREA Press, 2002), 127-131.

3 Spyros Ikonomopoulos, Costas Lambrinoudakis, Dimitris Gritzalis, Spyros Kokolakis, and Kostas Vassiliou, "Functional Requirements for a Secure Electronic Voting System," in Proceedings of the IFIP TC11 $17^{\text {th }}$ International Conference on Information Security (Cairo, 2002), 507-520.

4 Stefanos Gritzalis, Sokratis K. Katsikas, Dimitrios Lekkas, Konstantinos Moulinos, and Eleni Polydorou, "Securing the Electronic Market: the KEYSTONE Public Key Infrastructure Architecture," Computers and Security Journal 19, no. 8 (2000): 731-746.

5 Rolf Oppliger, "Managing Certificates in a Corporate Environment," Annals of Telecommunication 55, no. 7 (July 2000): 341-351.

6 Michael Sonntag, "Improving Communication to Citizens and within Public Administration by Attribute Certificates," in Knowledge Management in e-Government. KMGov-2001, Proceedings of the $2^{\text {nd }}$ International Workshop on Knowledge Management and Electronic Government (Siena, 2001), ed. Maria A. Wimmer (Linz: Universitätsverlag Rudolf Trauner, 2001), 207-217.

7 Salah Benabdallah, Sihem Guemara EI Fatmi, and Noureddine Boudriga, "Security Issues in e-Government Models: What Governments Should Do?" in 2002 IEEE International Conference on Systems, Man and Cybernetics (Hammamet, Tunisia, 6-9 October 2002), Volume 2, 398-403.

8 Noureddine Boudriga and Salah Benabdallah, "Laying out the Foundation for a Digital Government Model, Case Study: Tunisia," in Advances in Digital Government: Technology, Human Factors, and Policy, ed. W. McIver and A. K. Elmagarmid (Boston: Kluwer Academic Publishers, 2002).

9 Yumin Dong, Yannian Rui, and Dianxun Shuai, "The Researching of Constructing a Convenient, Safe, Credible, New e-Government System," in Proceedings of 2003 IEEE Intelligent Transportation Systems, Volume 2 (2003), 1719-1723.

${ }^{10}$ Karen Layne and Jungwoo Lee, "Developing Fully Functional e-Government: A Four Stage Model," Government Information Quarterly 18, no. 2 (2001): 122-136.

${ }^{11}$ Brahim Medjahed, Abdelmounaam Rezgui, Athman Bouguettaya, and Mourad Ouzzani, "Infrastructure for e-Government Web Services," IEEE Internet Computing 7, no. 1 (January/February 2003): 58-65.

12 Tatyana Podgayetskaya and Wolffried Stucky, "A Model of Business Process Support System for e-Government," in Proceedings of the $15^{\text {th }}$ International Workshop on Database and Expert Systems Applications (DEXA'04) (Zaragoza, Spain, 30 August-3 September 2004), (IEEE Computer Society, 2004),1007-1015. 
${ }^{13}$ Christopher G. Reddick, "A Two-Stage Model of e-Government Growth: Theories and Empirical Evidence for U.S. Cities," Government Information Quarterly 21, no. 1 (2004): 51-64.

${ }^{14}$ Costas Lambrinoudakis, Stefanos Gritzalis, Fredj Dridi, and Günther Pernul, "Security Requirements for E-Government Services: A Methodological Approach for Developing a Common PKI-based Security Policy," Computer Communications 26, no. 16 (2003): 18731883; Reddick, "A Two-Stage Model of e-Government Growth."

${ }^{15}$ Thurman L. Whitson and Lynn Davis, "Best Practices in Electronic Government: Comprehensive Electronic Information Dissemination for Science and Technology," Government Information Quarterly 18, no. 2 (2001): 79-91.

${ }^{16}$ Maria Wimmer and Bianca von Bredow, "E-Government: Aspects of Security on Different Layers," in Proceedings of $12^{\text {th }}$ IEEE International Workshop on Database and Expert Systems Applications "On the Way to Electronic Government" (Munich, Germany, 3-7 September 2001), ed. A. Min Tjoa and Roland Wagner (Los Alamitos, CA: IEEE Computer Society Press, 2001), 350-355.

${ }^{17}$ Maria Wimmer and Bianca von Bredow, "A Holistic Approach for Providing Security Solutions in e-Government," in Proceedings of the $35^{\text {th }}$ Hawaii International Conference on System Sciences (HICSS-35) (Big Island of Hawaii, 7-10 January 2002), (IEEE Computer Society, 2002), 1715-1724.

${ }^{18}$ Michael Gisler and Dieter Spahni, eds., E-Government: Eine Standortbestimmung (Bern: Paul Haupt, 2000).

${ }^{19}$ John F. Rockart, "The Changing Role of the Information Systems Executive: A Critical Success Factors Perspective," Sloan Management Review 24, no. 1 (1982): 3-13.

${ }^{20}$ Wimmer and Bredow, "A Holistic Approach for Providing Security Solutions in eGovernment."

${ }^{21}$ Min-Shiang Hwang, Iuon-Chung Lin, and Li-Hua Li, "A Simple Micro-payment Scheme," Journal of Systems and Software 55, no. 3 (January 2001), 221-229.

${ }^{22}$ Min-Shiang Hwang, Cheng-Chi Lee, and Yan-Chi Lai, "Traceability on Low-Computation Partially Blind Signatures for Electronic Cash," IEICE Fundamentals on Electronics, Communications and Computer Sciences E85-A, no. 5 (May 2002), 1181-1182.

${ }^{23}$ Min-Shiang Hwang, Eric Jui-Lin Lu, and Iuon-Chung Lin, "Adding Timestamps to the Secure Electronic Auction Protocol," Data \& Knowledge Engineering 40, no. 2 (February 2002): $155-162$.

${ }^{24}$ Min-Shiang Hwang, Cheng-Chi Lee, and Yan-Chi Lai, "An Untraceable Blind Signature Scheme," IEICE Transactions on Foundations E86-A, no. 7 (July 2003): 1902-1906.

${ }^{25}$ Ahti Saarenpää, Tuomas Pöysti, Mikko Saraja, Viveca Still, and Ruxandra Balboa-Alcoreza, "Data Security and Law: Perspectives on the Legal Regulation of Data Security," Executive Summary in English of the Research Report published by the Ministry of Finance under the title "Tietoturallisuusja laki, näkökohtia tietoturvallisuude oikeudellisesta sääntelystä," 1997.

${ }^{26}$ Noureddine Boudriga, "Technical Issues in Securing e-Government," in 2002 IEEE International Conference on Systems, Man and Cybernetics, (Hammamet, Tunisia, 6-9 October 2002), Volume 2 (2002), 392-397; Gritzalis and Lambrinoudakis, "Security Requirements of E-Government Services."

${ }^{27}$ Sonntag, "Improving Communication to Citizens and within Public Administration by Attribute Certificates." 
${ }^{28}$ Lambrinoudakis, Gritzalis, Dridi, and Pernul, "Security Requirements for e-Government Services."

${ }^{29}$ A. van Rensburg and Sebastiaan H. von Solms, "A Reference Framework for Certification Authorities/Trusted Third Parties," in Proceedings of the $13^{\text {th }}$ IFIP International Information Security Conference, ed. L. Yngstromand and J. Carlsen (Chapman \& Hall, 1996).

${ }^{30}$ Gwo-Chin Tai and Chung-Ming Ou "The Development of PKI Interoperability in Taiwan," in Proceedings of $37^{\text {th }}$ IEEE Annual 2003 International Carnahan Conference on Security Technology (14-16 October 2003), 405-409.

${ }^{31}$ Franco Arcieri, Giovanna Melideo, Enrico Nardelli, and Maurizio Talamo, "Experiences and Issues in the Realization of e-Government Services," in Proceedings of the 12th International Workshop on Research Issues in Data Engineering: Engineering $e$ Commercel e-Business Systems (RIDE'02) (San Jose, California, USA, February 2002), (Washington, DC, USA: IEEE Computer Society, 2002), 143-150.

${ }^{32}$ Michael Caloyannides, Dennis R. Copeland, George H. Datesman Jr., and David S. Weitzel, "US e-Government Authentication Framework and Programs," IT Professional 5, no. 3 (May/June 2003), 16-21.

${ }^{33}$ Chin-Chen Chang, Kuo-Feng Hwang, and Min-Shiang Hwang, "A Digital Watermarking Scheme Using Human Visual Effects," Informatica: An International Journal of Computing and Informatics 24, no.4 (2000), 505-511.

${ }^{34}$ Fernando Galindo, "Public Key Certification Providers and e-Government Assurance Agencies. An Appraisal of Trust on the Internet," in Proceedings of $12^{\text {th }}$ IEEE International Workshop on Database and Expert Systems Applications "On the Way to Electronic Government” (Munich, Germany, 3-7 September 2001), ed. A. Min Tjoa and Roland Wagner (Los Alamitos, CA: IEEE Computer Society Press, 2001), 345-349.

${ }^{35}$ Min-Shiang Hwang, Chin-Chen Chang, and Kuo-Feng Hwang, "Digital Watermarking of Images Using Neural Networks,” Journal of Electronic Imaging 9, no. 4 (2000): 548-555.

${ }^{36}$ Benabdallah, Guemara EI Fatmi, and Oudriga, "Security Issues in e-Government Models: What Governments Should Do?"

${ }^{37}$ Min-Shiang Hwang and Wei-Pang Yang, "A Two-Phase Encryption Scheme for Enhancing Database Security," Journal of Systems and Software 31, no.12 (December 1995): 257-265.

${ }^{38}$ Min-Shiang Hwang and Wei-Pang Yang, "Multilevel Secure Database Encryption with Subkeys," Data and Knowledge Engineering 22, no. 2 (April 1997): 117-131.

${ }^{39}$ Min-Shiang Hwang and Chii-Hwa Lee, "Secure Access Schemes in Mobile Database Systems," European Transactions on Telecommunications 12, no. 4 (July 2001): 303-310.

${ }^{40}$ Min-Shiang Hwang and Wei-Pang Yang, "Integrating Different Semantics of Classification Levels in Heterogeneous Distributed Database Systems," Pakistan Journal of Information and Technology 1, no. 1 (April 2002): 1-4.

${ }^{41}$ Ranjit Bose, "Information Technologies for Education \& Training in e-Government," in Proceedings of the International Conference on Information Technology: Coding and Computing (ITCC'04) (Las Vegas, Nevada, 05-07 April 2004), Volume 2 (IEEE Computer Society, 2004), 203-207.

${ }^{42}$ Steven Cohen and William Eimicke, "The Future of e-Government: A Project of Potential Trends and Issues," in Proceedings of the $36^{\text {th }}$ Hawaii International Conference on System Sciences (HICSS'03) (Big Island, Hawaii, 6-9 January 2003), (IEEE Computer Society, 2003), 146-155. 
${ }^{43}$ Ralf Klischewski and Martti Jeenicke, "Semantic Web Technologies for Information Management within e-Government Services," in Proceedings of the $37^{\text {th }}$ Hawaii International Conference on System Sciences (HICSS'04) (Big Island, Hawaii, USA, 5-8 January 2004), (Los Alamitos, California: IEEE Computer Society, 2004), 119-128.

${ }^{44}$ Iuon-Chang Lin , Min-Shiang Hwang, and Chin-Chen Chang, "Security Enhancement for Anonymous Secure e-Voting over a Network," Computer Standards \& Interfaces 25, no. 2 (May 2003): 131-139.

${ }^{45}$ Layne and Lee, "Developing Fully Functional e-Government: A Four Stage Model."

${ }^{46}$ Medjahed, Rezgui, Bouguettaya, and Ouzzani, "Infrastructure for e-Government Web Services."

${ }^{47}$ Podgayetskaya and Stucky, "A Model of Business Process Support System for eGovernment."

${ }^{48}$ Reddick, "A Two-Stage Model of e-Government Growth." 
MIN-SHIANG HWANG was born on August 27, 1960 in Tainan, Taiwan, Republic of China (R.O.C.). He obtained a B.S. degree in Electronic Engineering from National Taipei Institute of Technology, Taipei, Taiwan, R.O.C, in 1980; a M.S. degree in Industrial Engineering from National Tsing Hua University, Taiwan, in 1988; and a Ph.D. in Computer and Information Science from National Chiao Tung University, Taiwan, in 1995. He studied also Applied Mathematics at National Cheng Kung University, Taiwan, from 1984 to 1986. Dr. Hwang passed the National Higher Examination in the field "Electronic Engineer" in 1988. He also passed the National Telecommunication Special Examination in the field "Information Engineering" and qualified as advanced technician first class in 1990. From 1988 to 1991, he was the leader of the Computer Center at Telecommunication Laboratories (TL), Ministry of Transportation and Communications, R.O.C. He was also a chairman of the Department of Information Management, Chaoyang University of Technology (CYUT), Taiwan, during the period 1999-2002. He was a professor and chairman of the Graduate Institute of Networking and Communications, CYUT, during 2002-2003. He obtained the 1997, 1998, 1999, 2000, and 2001 Outstanding Research Award of the National Science Council of the Republic of China. He is currently a professor at the department of Management Information Systems, National Chung Hsing University, Taiwan, R.O.C. He is a member of IEEE, ACM, and the Chinese Information Security Association. His current research interests include electronic commerce, database and data security, cryptography, image compression, and mobile computing. Dr. Hwang has published over 100 articles in the above research fields in international journals. Address for correspondence: Department of Management Information System, National Chung Hsing University, 250 Kuo Kuang Road, 402 Taichung, Taiwan, R.O.C.; E-mail: mshwang@nchu.edu.tw.

CHUN-TA LI received a B.S. degree in Management Information Science from Chia Nan University of Pharmacy \& Science, Tainan county, Taiwan, Republic of China, in 2002. Two years later, he received a M.S. in Information Management from Chaoyang University of Technology, Taichung county, Taiwan. He is currently pursuing his Ph.D. degree in Computer Science from National Chung Hsing University. His current research interests include full text retrieval, information security, electronic government, and cryptography. Address for correspondence: Department of Computer Science, National Chung Hsing University, 250 Kuo Kuang Road, 402 Taichung, Taiwan, R.O.C. E-mail: phd9307@cs.nchu.edu.tw.

JAU-JI SHEN received a B.S. degree in Mathematics from Fu Jen University, Taipei county, Taiwan, Republic of China, in 1982. Two years later, he received a M.S. degree in Information Science program of Applied Mathematics from National Chung Hsing University, Taichung, Taiwan. In 1988, he received a Ph.D. in Information Engineering and Computer Science from National Taiwan University, Taipei, Taiwan. From 1988 to 1994, he was the leader of the software group at the Institute of Aeronautic, Chung Sung Institute of Science and Technology, R.O.C. He is currently an Associate Professor and Library Curator, National Formosa University, Taiwan, R.O.C. His current research interests include database techniques, algorithms, and software engineering. Address for correspondence: Department of Information Management, National Formosa University, 64 Wen-Hua Road Huwei, 632 Yunlin, Taiwan, R.O.C. E-mail: amitofo@sunws.nhust.edu.tw.

YEN-PING CHU is a Professor at the Department of Computer Science and the chair of Management Information Systems at National Chung Hsing University, Taiwan, R.O.C. His research interests include high-speed networks, operating systems, neural networks and computer-assisted learning. E-mail: ypchu@nchu.edu.tw. 